\title{
The Use of Information and Communication Technology to Promote the Interest of Learning Chemistry
}

\author{
Nataša Junež \\ Gimnazija Bežigrad, Secondary School, Ljubljana, Slovenia \\ Email address: \\ natasa.junez@gimb.org \\ To cite this article: \\ Nataša Junež. The Use of Information and Communication Technology to Promote the Interest of Learning Chemistry. Science Journal of \\ Education. Vol. 5, No. 5, 2017, pp. 220-224. doi: 10.11648/j.sjedu.20170505.17
}

Received: September 18, 2017; Accepted: October 14, 2017; Published: November 16, 2017

\begin{abstract}
Among young people a decline in interest for science and also the decline in understanding of science has been noticed. The traditional form of teaching, which are largely based on the theoretical interpretation of scientific ideas and scientific theories, do not contribute enough to improve the situation. One possible solution to this problem is the approach of teaching chemistry in context, which has its origins in the beginning of the eighties. In general colleges during the 1st year the Gas laws has been carried out in the learning unit with a different approach of teaching chemistry - teaching in context. The use of context was implemented, where the concepts are connected with the day-to-day life and social issues in the area of teaching chemistry. A learning unit is presented with the use of the program called exe, by which enabled the presentation of films, animations and solving of applied tasks on the interactive whiteboard. Students had access to the learning unit also via the online classroom Moodle. The purpose of my learning unit of the Gas laws was to improve secondary school teaching methods and learning chemistry with the aim of improving the quality of knowledge of students, as well as sustainable knowledge and interest of pupils for learning chemistry. The presentation of the gas laws using information and communication technology in the classroom has increased the interest of pupils for learning chemistry.
\end{abstract}

Keywords: Contemporary Approaches of Teaching, Virtual Classroom, Interest

\section{Introduction}

The findings of researchers about the fact that the interest of young people for science is decreasing [1] show the need of research in this area. Gilbert [1] summarizes some of the most likely reasons for a low interest of students: (1) too much material in the curricula; (2) lack of connection among the discussed concepts; (3) lack of linkage with problems, or solving problems in everyday life; and (4) lack of relevance of content and emphasis on irrelevant content and objectives.

In teaching and designing curriculum each of these reasons represents a series of challenges. As one of the possible solutions some authors cite the implementation of learning and teaching approach with the use of the context, in which the chemical concepts are associated with life. Examples of the approach with the use of context are e.g.: in Great Britain the project of "Salters", which started in 1983, when a group of teachers met in York to discuss ways on the basis of which chemistry would become more interesting for pupils and students [2]. Watters states that the project proved to have been very successful, as it was shown that the chemistry at Alevel is chosen by a larger number of pupils. A similar approach was started to be introduced in Germany [3] and in the Netherlands. The project "Chemie im Kontext" (ChiK) followed the ideas and experiences of the project Salters and started in the year 1997 in Germany. The purpose of this project was to on the one hand improve secondary school teaching and learning, and on the other hand to support cooperation among teachers, as well as between the teachers and the mentors at universities. In the Netherlands, the PLON is an approach with the use of the context in which the terms are associated with life in the field of teaching physics [4]. Project Chemistry and Practice, in short ChiP, refers to the important connection between learning chemistry and day-today life and social issues. Examples of this approach are seen in the United states of America ChemCom: Chemistry in the Community, secondary school textbook, which was developed with the support of the American Chemical Society (ACS) and the National Science Foundation (NSF), and Chemistry in Context $(\mathrm{CiC})$, which aimed at students of 
undergraduate programmes colleges and universities (student aged 18-20 years) in different fields of studies. The purpose of the group of six university professors, the authors of the $\mathrm{CiC}$, was to improve chemical literacy of Americans.

In a systematic review of articles on the application of the approach to teaching and learning chemistry through the use of context and evaluations of this approach (for students aged between 11 and 18 years) from the year 1980 onward, Bennett [2] notes that there are 44 articles which reported on the impact of the approach on the interest of pupils for natural sciences, 41 of them were devoted to studying the knowledge from the field of science acquired with this approach, and 24 publications contained both these terms. 17 studies reported on the impact of gender on the interest of the pupils and 7 study the role of skills of students. Among the articles that were based on experimental studies, they reported the results in the following areas: 1) reports on the understanding of science on the application of the approach of teaching and learning chemistry through the use of context compared to traditional lectures (for a better understanding of the students when teaching using the approach of context -4 articles; comparative understanding of the students using both approaches -8 articles; worse understanding of the students when teaching the use of context -1 study);2) the evaluation of the attitude towards science in school and science on the application of the approach teaching and learning chemistry through the use of context compared to traditional lectures (an improved attitude of students when teaching using the approach of context -7 articles; the same attitude -2 of the article); 3) study of the role of gender and skills of students in learning at the application of the approach teaching and learning chemistry through the use of context compared to traditional lectures (reduction of the differences in attitude to science between the sexes when using the approach of context -3 articles; girls have a more positive attitude towards science than boys on the application of the approach context -2 of the article; the students with lower abilities at the application of the approach context to develop a better understanding of the natural sciences -1 article).

Due to the problems in studies of attitudes toward science perceived in literature, Bennett and Hogarth [4] report on the development and the standardization of the instrument with the title Attitude of the natural sciences in the school of natural sciences, which enables simultaneous collection of descriptive and expansionary data for the age group 11-16 years. The results of the study show that the students see the natural sciences in their environment more positively in comparison with experience in teaching. The impacts on students aged 11 and 14 are considered to be the key impacts for the formation of attitudes towards science. In support of the understanding of the development of interest in students Hidi and Renninger [5] have developed the four-stage model of the development of interest. In the model, the first stage institution is the situation of interest which develops into a dependent situation of interest (second stage), third stage is emergent individual interest, which in the fourth stage leads to a well-developed individual interest. The results of the research show that the person must be exposed to stimulus or have a minimal level of knowledge from a certain field, for the interest to be triggered. Also in the case of genetic predisposition for a particular activity may be the interest be triggered and developed only if a person has the appropriate model, the instructions and options for it available. Among the few alternatives of the development of interest the most connected are: a) models of the divisional learning - MDL, b) personal-subject theory of interest - POI, c) psychology of the creative whim. The four-phase model of interest builds on the aspects of these and also differs from them. MDL gives situational interests priority to the development of the individual. The situation of interest has a greater importance in the early stages of connecting learning. MDL describes the evolution of interest in connection with the personal development of the implementation opinions and academic knowledge. Interest was supposed to be some kind of spark, which helps to maintain student's investment, as long as this does not come to a final solution of the problems. Interest is described as parallel to the development and acquisition of knowledge. Students in their early years, when getting information from the teachers, also cannot develop expertise. The four-stage model of interest is different from the MDL in that it claims that the situation of interest does not arise with an individual, when it is already developed. A four-stage model of interest is different from the MDL in: 1 . Interest exists in connection between the person and his surroundings. 2. Even for small children it can be argued to have a one-to-one interest. 3. Stages of development of interest undergo a complete change. If there is no continued support for such interaction, the interest is not present. 4 . Even without a well-developed individual interest, it is possible to have expertise (e.g. technicians, who work with $\mathrm{x}$ rays).

POI is orientated primarily on the individual interest, which arises in the connection between the person and the surroundings. Like a four-stage model of interest, the interest is specific and not a general, connected with positive emotions. Interest is composed of connection of values and emotions, which is in contrast with the four-stage model of the development of interest. In a four-stage development model for the interest the impact model is identified as a full part which in conjunction with the knowledge gives the whole value. Emotions that have the competence, autonomy and social similarities also support the student's development and deepen the interest. Renninger [6] discovered that the 1113-year-old students who did not achieve good results in tests, but had a well-developed individual interest for reading or math, were probably better at solving problems on the substances than students with high abilities, but with a less developed individual interest. Research has shown that teachers can support a) interest for the subject, even if set as a research task, as it encourages the development of individual interest, which supports student's further formation of their own questions out of curiosity, b) that students themselves choose, or solve the tasks with the 
problems and at the same time learn the way to find solutions to the problems. In the early stages of the development of interest it is proven that positive feelings about yourself activities and solutions to solve problems are important if students are focused only on the content.

[7] Sansone and colleagues have discovered that pupils in the last years of school (high school) can develop a solid situation interest for the substance of which they had not previously had much knowledge or emotions. These students quickly pass from the development of the situational interest in emerging individual interest. Interest can develop to this level, if students find the reasons for the conquest of a given substance. It certainly leads the way in the development of individual interest in curiosity for a specific substance and the formation of questions about the substance. These questions lead to the acquisition, storage and completion of new knowledge.

Other studies explain a lot about the attitude of students to science in the first grades of high school. In the meantime, the students begin to reflect critically on teachers and further career related to science. On the basis of a study of the literature it can be summarized that further studies are needed both in evaluation quality, as well as the durability of knowledge of pupils acquired when using the approach to teaching and learning chemistry through the use of context in comparison with the traditional approach to teaching chemistry. We assume that there is a difference in performance in the implementation approach of learning and teaching of chemistry using the context of which different authors reported, in addition to the specific characteristics of pupils (gender, age of students, general skills of students and the social environment of the pupils), also due to the role of the teacher and the selection of concrete activities in the class to let students develop interest in learning.

[8] The context-based curriculum itself becomes a template for educating students as members of society, informed about issues of importance to humankind such as global warming and clean water supply. Most importantly, context-based learning returns the curriculum to a focus on informed students learning about the process of how we do science.

Edosomwan J. H. and T. O. [9] have discovered that the teacher should take time to understand the socio-economic status of his students; he should not discriminate them in class, but always motivate them irrespectively of their socioeconomic status. The study has shown that students' attitudes to computer science are very important in learning computer science. Therefore, teacher should adopt various instructional strategies that would remove negative or unfavourable attitude to science. Teachers should start from known to unknown and from concrete to abstract topics so as to enhance students understanding and learning of science. If the above approach is adopted by the teacher, this could lead to optimum and maximum learning attainment on the part of the learners. According to Zane Education [10], over 94\% of teachers have effectively used video in a given academic year to aid teaching in their classrooms. This study showed that the use of video-taped instruction in teaching and learning of physics practically improves students' performance and also solves the problem of unavailability/shortage of practical equipment as against the number of students in a class. Shredrack's and Robert James's study [11] showed that the use of video-taped instruction in teaching and learning of physics practically improves students' performance. The use of videotape in education has always been positive, especially in physics and chemistry, but does not produce tangible effects in languages and literature [12].

[13] Loveridge said: "Forget arts versus sciences. Discipline rivalry is alive and well within the sciences and even within chemistry itself, and it could be doing our students harm. We need to be aware that making divisions between disciplines influences our students' thinking, often in unintended ways".

I used program exe as a different approach to teaching. For teaching in the context I used terms associated with the dayto-day life and social issues. The learning unit Gas laws was presented with the use of the program exe, by which it was possible to show the presentation of films, animations and solve applied tasks on the interactive whiteboard.

\subsection{Work in the Classroom}

The learning unit in the classroom was implemented in 3 lesson with the help of the program exe, stored in the online classroom of Gimnazija Bežigrad. It was shown with the help of interactive whiteboards. In the unit events from everyday life as the introductory motivation were used. Diving and jumping in the depth were presented with two images, and with the question: "Why can be diving or jumping in the depth dangerous?" Responses with the examples of the values of pressures at different heights and the depths of the sea in conjunction with a variety of volume of the balloon were given. These cases served as a starting point for answering the question: "How many times are the lungs of the diver reduced at the depth of $150 \mathrm{~m}$ ?"

Image for introductory motivation in learning unit:

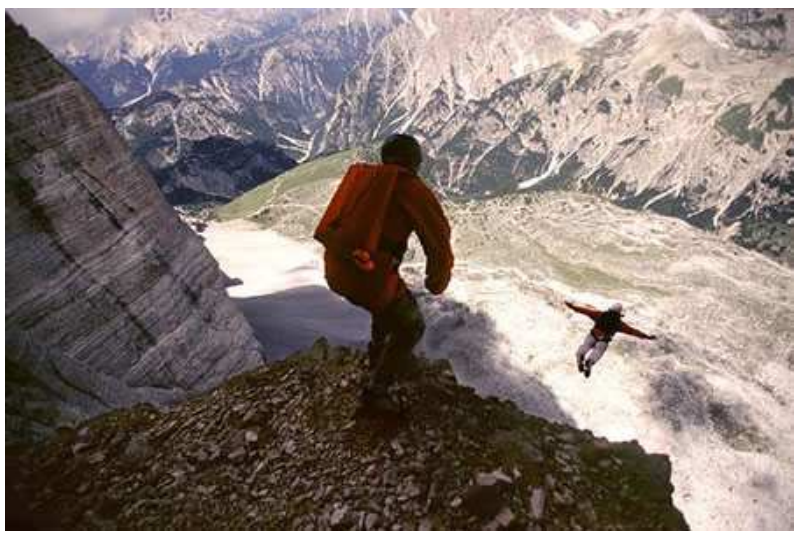

Figure 1. BASE jumping, Wikipedia, available on the website: http://sl.wikipedia.org/wiki/BASE_jumping[cited 23.5.2008].

In my learning unit I presented a short clip from the film (directed by Luc Besson), Big blue, where one of the main 
characters sinks at the depth of $108 \mathrm{~m}$. The students could verify their understanding of the unit by solving interactive tasks.

The interactive task in the learning unit:

Molar volume of the gas - repetition of the substance

Read the following argument and insert the missing words or numbers.

Volume mole of gas at temperature or pressure is molar volume of the gas. 1 mole gas has the same volume at the same temperature and pressure.

Additionally, the students could consolidate their knowledge by observing animations of the same number of gas molecules in two different containers at different conditions, different volume and temperature. They had to determine, in which container the temperature of the gas was higher. They could verify their answers. They were able to use a tip that had already been written.

The students also had the option to obtain the theoretical knowledge by solving the tasks for which they had the solution written in the classical form. In the classical way they prefer to learn at home.

Table 1. The task with the use of animations in the learning unit.

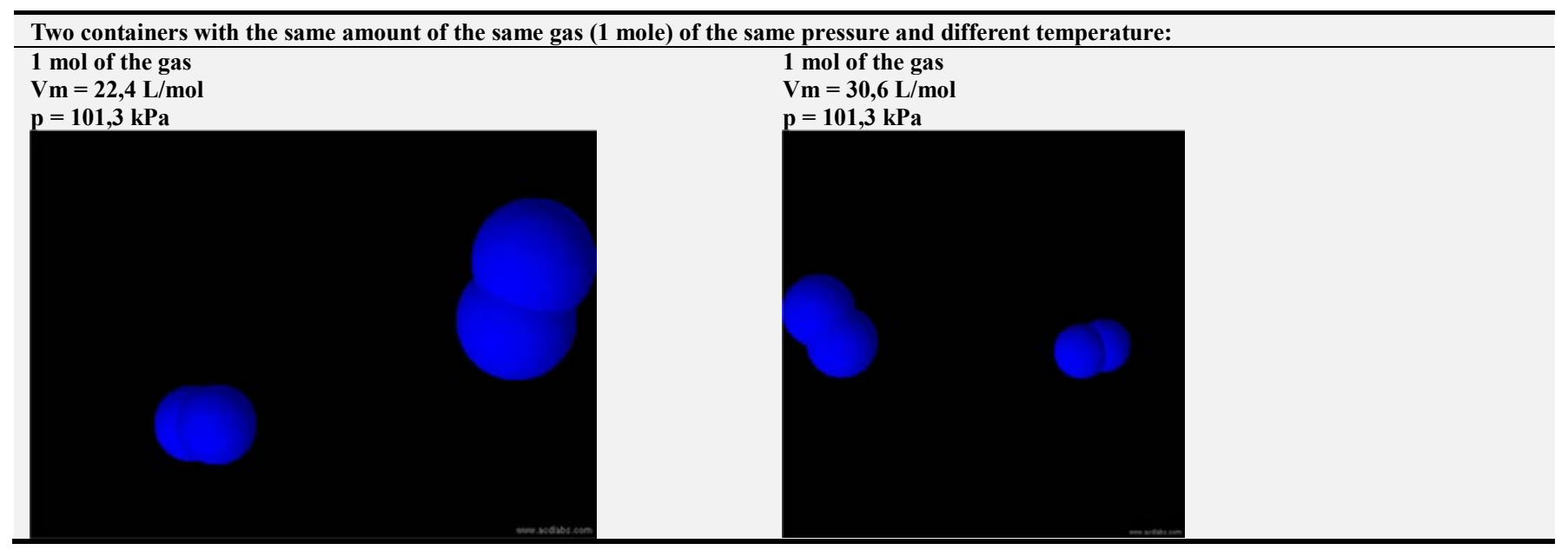

Animation 1: Nataša Junež, the Movement of molecules of nitrogen in a small container.

Animation 2: Nataša Junež, the Movement of molecules of nitrogen in a larger container.

In which container is the temperature of the gas higher?

Hint: watch the speed of movement of gas molecules in both containers.

The temperature of the gas in the second container is higher, as well as the molecules of gas are moving faster.

\subsection{Work at Home}

An example of the classical tasks in the learning unit:

Calculate the mass of the gas in the first container (at given conditions of the gas), if we know that nitrogen is in the container.

The calculation should contain:

- the formula of the gas equation

- the derivation of the mass of the gas

- result.

It can be shown (from the data) that the temperature of the gas in the first container is $273 \mathrm{~K}$

Calculation:

$$
\begin{gathered}
\mathrm{p} * \mathrm{~V}=\mathrm{n} * \mathrm{R} * \mathrm{~T} \\
\mathrm{p} * \mathrm{~V}=(\mathrm{m} / \mathrm{M}) * \mathrm{R} * \mathrm{~T} \\
\frac{\mathrm{P} * \mathrm{~V} * \mathrm{M}}{\mathrm{R} * \mathrm{~T}}=m
\end{gathered}
$$

$$
\begin{gathered}
\frac{101,3 * 10^{3} * N * m^{-2} * 22,4 * 10^{-3} * m^{3} * 28,0 * 10^{-3} * \mathrm{~kg}^{2} \mathrm{~mol}^{-1}}{8,31 \mathrm{~N} * \mathrm{~m} * \mathrm{~mol}^{-1} * K^{-1} * 273 * K}=m \\
\mathrm{~m}=28,0 * 10^{-3} \mathrm{~kg}= \\
\mathrm{m}=28,0 \mathrm{~g}
\end{gathered}
$$

There is $28.0 \mathrm{~g}$ of nitrogen (molecules of $\mathrm{N}_{2}$ ) in the first container.

Learning unit continues with the theoretical presentation of three gas laws, with the use of animation of gas molecules, with a short film showing the increase in pressure on the balloon, an interactive task and a graphical representation of an isotherm change. All three gas laws were included in the gas equation.

Learning unit The ideal gas equation is fully accessible in the online classroom, Gimnazija Bežigrad Moodle: http://www.Moodle.gimb.org [14].

\section{Methods}

This research was carried out in $1^{\text {st }}$ year of secondary school in Gimnazija Bežigrad, Ljubljana, Slovenia. The population of this study was comprised of two $1^{\text {st }}$ classes of the secondary school, together 64 students.

One class represented the experimental group (31 students), the other represented the control group (33 students).

The instrument used was the option of the students for chemistry as an optional subject. The quality of the 
knowledge was measured with the test results, which had been written by students after the treatment of the learning unit.

\section{Result}

In $1^{\text {st }}$ year of secondary school, where I have given the presentation, 28 students out of 31 from the experimental group opted for chemistry as an optional subject. The number of those who opted for chemistry as an optional subject in the control group was only 10 .

\section{Discussion}

Computer generation of animations in the learning unit caused quite a few problems to me as I had to widen my knowledge of using a computer. A great help to me were acquaintances, to whom I could turn with questions. The main problem in the online classroom (Moodle) was the presentation of the parts of the film of the learning units. They were not visible without the right players. Computer scientist at our school has always helped me solve the problems associated with Moodle. Usually I teach in a classic way, because making similar teaching units require a lot of knowledge and time. To view the events of life, especially of chemical experiments in the future I would like to use more classroom teaching units in the program exe and online classroom.

\section{Conclusion}

From the point of view of improving the quality of the knowledge and interest of the pupils against the learning objectives, we pay special attention to problem-solving-tasks with various forms of excitation interest of the pupils. The use of ICT technology has proven to be very useful, especially using online classroom (Moodle) because of the implementation of the posts school work tasks and the storage of students' products. Also the use of interactive whiteboards in connection with the world wide web fosters the students' interest in learning chemistry. In $1^{\text {st }}$ year of secondary school, where I have given the presentation, 28 students out of 31 opted for chemistry as an optional subject. The use of context was implemented, where the concepts are connected with the day-to-day life and social issues in the area of teaching chemistry. Gas laws were presented at the end of the school year and were related to the content in the learning unit as well as to the extract from a movie about diving in that learning unit, nevertheless at that time a lot of students were also preparing to go to the seaside.

The quality of the knowledge was visible from the test results which students had been written after the treatment of the learning unit. The test results of both groups were not significantly different and they were expected, because the learning abilities of students of both groups are very high.

\section{References}

[1] Gilbert J. (2006). On the nature of »Context« in Chemical Education. International Journal of Science Education, Vol. 28, No. 9, 14 July 2006, pp. 957-976.

[2] Bennett, J. (2006b). Context-based Chemistry: The Salters approach. International Journal of Science Education. Vol. 28, No. 9, 14 July 2006, pp. 999-1015.

[3] Parchmann I. (2006). "Chemie im Kontext". A symbiotic implementation of a context-based teaching and learning approach. International Journal of Science Education, Vol. 28, No. 9, 14 July 2006, pp. 1041-1062.

[4] Bennett J., Hogarth S. (2009). Would You Want to Talk to a Scientist at a Party? High school students' attitudes to school science and to science, International Journal of Science Education.

[5] Hidi S, Renninger A. K. (2006). The Four-Phase Model of Interest Development; Educational psychologist, Vol. 41, 2006, pp. 111-127.

[6] Renninger, K. A. (1990). Children's play interests, representation, and activity. In R. Fivush\&K. Hudson (Eds.), Knowing and remembering in young children, pp. 127-165. New York: Cambridge University Press.

[7] Sansone, C.\& Smith, J. L. (2000). Interest and self-regulation: The relation between having to and wanting to. In C. Sansone \& J. M. Harackiewicz (Eds.), Intrinsic and extrinsic motivation: The search for optimal motivation and performance, pp. 341-37. New York: Academic. Sansone.

[8] Seery M. (2015). Putting chemistry in context. Education in Chemistry, pp. 17-19.

[9] Edosomwan J. H., Edosomwan T. O. (2015). Correlation Between Attitude and Socio-Economic Status of Students' Performance in Computer Science. Science Journal of Education. Vol. 3, No. 4, 2015, pp. 75-77.

[10] Zane Education. (2016). The benefits of using educational video in the classroom. Retrieved September 28th, 2016.

[11] Shedrack T., Robert James J. (2016). Effect of Video-Taped Instruction on Senior Secondary Students' Performance in Physics Practical in Port-Harcourt Metropolis, Nigeria. Science Journal of Education. Vol. 4, No. 6, 2016, pp. 169174.

[12] Karimi. M. H., Derakhashan, A., Valai N., \& Mortazavi, F. (2003). The effectiveness of video-based education on gaining practical learning skills in comparison with demonstrating method's effectiveness among universities' students. Journal of Medical Education. 4 (1), 27-30.

[13] Loveridge J. (2017). Adopting an open minded approach to interdisciplinary science. Education in Chemistry, Retrieved October 18th, 2017.

[14] Junež N. (2008). The ideal gas equation. Learning unit. 